\title{
Enhanced Efficiency of GaAs Single-Junction Solar Cells with Inverted-Cone-Shaped Nanoholes Fabricated Using Anodic Aluminum Oxide Masks
}

\author{
Kangho Kim, ${ }^{1}$ Hoang Duy Nguyen, ${ }^{2}$ Sunil Mho, ${ }^{3}$ and Jaejin Lee ${ }^{1}$ \\ ${ }^{1}$ Department of Electrical and Computer Engineering, Ajou University, Suwon 443-749, Republic of Korea \\ ${ }^{2}$ Institute of Applied Materials Science, Vietnam Academy of Science and Technology, Ho Chi Minh 70999, Vietnam \\ ${ }^{3}$ Department of Energy Systems Research, Ajou University, Suwon 443-749, Republic of Korea
}

Correspondence should be addressed to Jaejin Lee; jaejin@ajou.ac.kr

Received 15 June 2013; Accepted 10 July 2013

Academic Editor: Leonardo Palmisano

Copyright (C) 2013 Kangho Kim et al. This is an open access article distributed under the Creative Commons Attribution License, which permits unrestricted use, distribution, and reproduction in any medium, provided the original work is properly cited.

The GaAs solar cells are grown by low-pressure metalorganic chemical vapor deposition (LP-MOCVD) and fabricated by photolithography, metal evaporation, annealing, and wet chemical etch processes. Anodized aluminum oxide (AAO) masks are prepared from an aluminum foil by a two-step anodization method. Inductively coupled plasma dry etching is used to etch and define the nanoarray structures on top of an InGaP window layer of the GaAs solar cells. The inverted-cone-shaped nanoholes with a surface diameter of about $50 \mathrm{~nm}$ are formed on the top surface of the solar cells after the AAO mask removal. Photovoltaic and optical characteristics of the GaAs solar cells with and without the nanohole arrays are investigated. The reflectance of the AAO nanopatterned samples is lower than that of the planar GaAs solar cell in the measured range. The short-circuit current density increased up to $11.63 \%$ and the conversion efficiency improved from 10.53 to $11.57 \%$ under 1-sun AM $1.5 \mathrm{G}$ conditions by using the nanohole arrays. Dependence of the efficiency enhancement on the etching depth of the nanohole arrays is also investigated. These results show that the nanohole arrays fabricated with an AAO technique may be employed to improve the light absorption and, in turn, the conversion efficiency of the GaAs solar cell.

\section{Introduction}

GaAs is commonly used to fabricate the high conversion efficiency III-V solar cell based on multijunction tandem structure. An InGaP layer is utilized as a window layer on top of the GaAs emitter in a GaAs-based solar cell. Because of refractive index difference between $\mathrm{InGaP}$ and air, more than $30 \%$ of the incident light can be reflected from the surface of the solar cells [1]. It is therefore necessary to use an antireflection coating layer for improving the conversion efficiency. An antireflection coating using multilayers with different refractive index materials such as $\mathrm{MgF}_{2}, \mathrm{ZnS}, \mathrm{ZnO}$, $\mathrm{SiO}_{2}, \mathrm{SiN}_{x}$, and $\mathrm{TiO}_{x}$ is usually used for the conventional solar cells [2-4]. However, this layer can invoke unexpected problems such as adhesion and thermal mismatch when the solar cell operates under the strong-irradiation condition. To overcome these drawbacks, surface texturing techniques have been successfully introduced [1,5-7]. By patterning the window surface layer, one can significantly reduce the reflection of the incident light through the enhanced absorption from the textured structures. Nanopatterning structures using metal nanoparticles or photonic crystal have attracted much attention because they can improve the light absorption due to the plasmonic and spontaneous effects $[8,9]$. Several groups reported on using two-dimensional photonic crystals to improve conversion efficiency of $\mathrm{Si}$ or $\mathrm{Ge}$ solar cells $[10,11]$. However, using expensive nanopatterning technique such as electron-beam lithography increases device cost significantly. Therefore, nonlithographic approach using nanoporous anodic aluminum oxide (AAO) template has attracted a lot of attention as a key nanofabrication method due to its simple and low-cost process [12]. Moreover, with the AAO mask, we can fabricate the nanohole arrays with a small diameter (below $100 \mathrm{~nm}$ ) that is difficult to make by 
the conventional lithography methods. It is worth noting that by using such a small opening mask, we can fabricate the nanoholes with an inverted cone shape that is close to the optimized form for the light-management architectures to achieve the high-efficiency solar cells [13].

In this study, we report on the improvement of the GaAs solar cells with the nanohole arrays on the InGaP window layer. The AAO masks with an opening size of about $50 \mathrm{~nm}$ are prepared using a two-step anodization process. The inverted-cone-shaped (ICS) nanoholes with different depths are formed on the surface of the solar cell after inductively coupled-plasma reactive-ion-etching (ICP-RIE) processes. The conversion efficiency improved from 10.53 to $11.57 \%$ under 1-sun AM $1.5 \mathrm{G}$ conditions by using the nanohole arrays.

\section{Experiment Details}

The GaAs single-junction solar cell structures, as shown in Figure 1, are grown in a metalorganic chemical vapor deposition (MOCVD) system on n-type GaAs (100) substrates. Trimethylgallium (TMGa) and trimethylindium (TMIn) are used as group III precursors, while arsine $\left(\mathrm{AsH}_{3}\right)$ and phosphine $\left(\mathrm{PH}_{3}\right)$ are used as As and $\mathrm{P}$ sources, respectively. Silane $\left(\mathrm{SiH}_{4}\right)$ and diethylzinc (DEZn) are used as $\mathrm{n}$ - and p-doping sources, respectively. Ultra-high purity hydrogen gas $\left(\mathrm{H}_{2}\right)$ is used as a carrier gas. The reactor pressure and temperature are kept at $50 \mathrm{mbar}$ and $680^{\circ} \mathrm{C}$, respectively. Device structures from the substrate to the top consist of a $0.2 \mu \mathrm{m}$ thick GaAs buffer layer for high crystal quality, a $0.05 \mu \mathrm{m}$ thick highly doped $\mathrm{In}_{0.5} \mathrm{Ga}_{0.5} \mathrm{P}$ back surface field (BSF) layer, a $3.5 \mu \mathrm{m}$ thick GaAs base layer, a $0.5 \mu \mathrm{m}$ thick GaAs emitter layer, a $0.2 \mu \mathrm{m}$ thick highly doped $\operatorname{In}_{0.5} \mathrm{Ga}_{0.5} \mathrm{P}$ window layer, and a $0.3 \mu \mathrm{m}$ thick GaAs cap layer for ohmic contact.

The solar cell devices with the aperture area of $0.25 \mathrm{~cm}^{2}$ are made using conventional fabrication processes. Metal contacts are defined by a UV photolithography technique. $\mathrm{AuGe} / \mathrm{Ni} / \mathrm{Au}$ and $\mathrm{Ti} / \mathrm{Pt} / \mathrm{Au}$ layers are deposited by an ebeam evaporator for the $\mathrm{n}$ - and p-type ohmic contacts, respectively. The samples then are annealed in an RTA station at $385^{\circ} \mathrm{C}$ for $30 \mathrm{~s}$. The InGaP window layer is exposed by selectively etching $\mathrm{p}^{+}$-GaAs cap layer in an acid solution $\left(\mathrm{CA}: \mathrm{H}_{2} \mathrm{O}_{2}: \mathrm{H}_{2} \mathrm{O}=25: 1: 75\right)$.

Nanohole arrays are patterned on the surface of the solar cell by an ICP-RIE etching using the AAO mask. The AAO masks are prepared by a typical two-step anodization process using a grain-free aluminum foil $(99.99 \%, 100 \mu \mathrm{m}$ in thickness, Tokai). The aluminum foil is electropolished in a 1:4 solution of perchloric acid and ethanol. After the first anodization in the $0.3 \mathrm{M}$ oxalic acid at $40 \mathrm{~V}$ for $8 \mathrm{~h}$, the anodized oxide layer on the $\mathrm{Al}$ foil is removed in a mixture of $\mathrm{H}_{3} \mathrm{PO}_{4}$ and $\mathrm{CrO}_{3}$. The sample is then exposed for the second anodization step resulting in a thin alumina film of 500$600 \mathrm{~nm}$ on top of the $\mathrm{Al}$ foil by controlling the anodization duration. A saturated $\mathrm{HgCl}_{2}$ solution is used to remove the Al film at the bottom, leaving a thick anodized alumina layer. The removal of the barrier layer and hole widening are conducted in a $5 \mathrm{wt} \% \mathrm{H}_{3} \mathrm{PO}_{4}$ solution. The $\mathrm{AAO}$ masks

\begin{tabular}{|c|c|c|}
\hline \multicolumn{2}{|c|}{ Front contact $(\mathrm{Ti} / \mathrm{Pt} / \mathrm{Au})$} & $500 \mathrm{~nm}$ \\
\hline Ohmic & $p$-GaAs & $300 \mathrm{~nm}$ \\
\hline Window & $p-\ln _{0.5} \mathrm{Ga}_{0.5} \mathrm{P}$ & $200 \mathrm{~nm}$ \\
\hline Emitter & $p$-GaAs & $500 \mathrm{~nm}$ \\
\hline Base & $n$-GaAs & $3500 \mathrm{~nm}$ \\
\hline BSF & $n-\ln _{0.5} \mathrm{Ga}_{0.5} \mathrm{P}$ & $50 \mathrm{~nm}$ \\
\hline Buffer & $n$-GaAs & $200 \mathrm{~nm}$ \\
\hline Substrate & $n$-GaAs & $350 \mu \mathrm{m}$ \\
\hline Back conta & $\mathrm{Ge} / \mathrm{Ni} / \mathrm{Au})$ & $500 \mathrm{~nm}$ \\
\hline
\end{tabular}

FIGURE 1: Schematic structure of the fabricated GaAs single-junction solar cells.

are designed with a hole size of about $40 \mathrm{~nm}$ and a distance between holes of about $100 \mathrm{~nm}$ in a quasihexagonal geometry [14]. The AAO mask is placed on top of the GaAs solar cell structure. ICP-RIE etching is then applied to transfer the nanopattern from the AAO mask to the window layer of the solar cell. The etching process uses a mixture of $\mathrm{BCl}_{3}$ and $\mathrm{Cl}_{2}$ with the flows of 5 and $30 \mathrm{sccm}$, respectively, under an ICP source power of $200 \mathrm{~W}$ and an RF bias power of $50 \mathrm{~W}$ at a chamber pressure of 10 mTorr. The depths of the nanohole arrays are controlled by etching time that is varied from 10 to $60 \mathrm{~s}$. The nanohole arrays are finally formed on top of the GaAs solar cell after removing the AAO masks. A GaAs solar cell without the nanohole pattern is used as a reference for the solar cell performance investigation. The morphologies of the GaAs solar cell with the nanohole arrays are studied by a field emission scanning electron microscopy (FE-SEM). To study the loss of the incident light, we carried out reflectance measurements at room temperature with a UVVis-NIR Cary 5000 Spectrometer from 300 to $900 \mathrm{~nm}$. The photovoltaic current density-voltage $(J-V)$ characteristics of the GaAs solar cells are evaluated by a solar simulator under 1-sun air mass (AM) 1.5 G-conditions at room temperature. The photocurrent response of the fabricated cells is also investigated with a quantum efficiency measurement system at room temperature.

\section{Results and Discussions}

Figure 2 shows the SEM images of the nanohole arrays on the solar cells. After a $40 \mathrm{~s} \mathrm{ICP/RIE} \mathrm{etching} \mathrm{and} \mathrm{removal} \mathrm{of}$ the AAO mask, the nanohole arrays have the quasihexagonal symmetry with a mean diameter and depth of about 50 and $64 \mathrm{~nm}$, respectively. The holes that formed on top of the solar cells are slightly larger than those of the AAO masks because the AAO masks may be etched out during the plasma etching process and/or the surfaces of solar cells in contact with the AAO masks are not completely smooth [12]. It is worth to note that the nanohole arrays retain an ICS form as can be observed clearly in the inset of Figure 2(b). The ICS nanoholes can be formed after a short-time dry etching process using masks with a small opening [15]. The depths of 


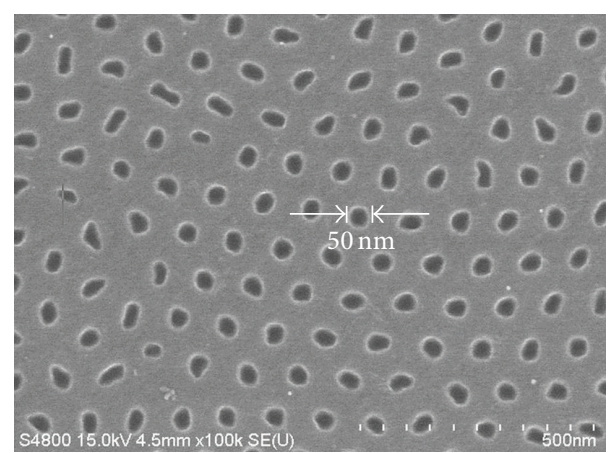

(a)

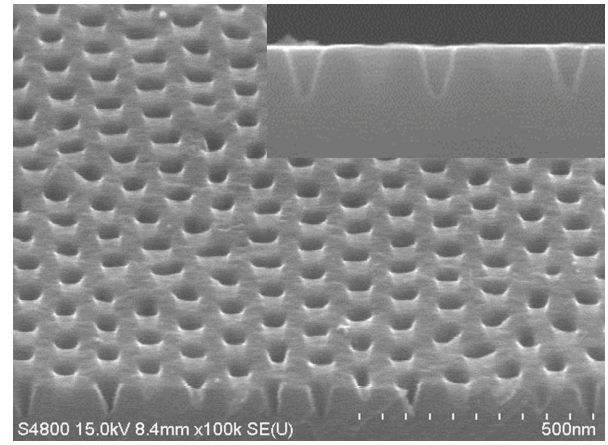

(b)

Figure 2: (a) Top- and (b) tilt-view FE-SEM images of the nanohole arrays formed on the InGaP window layer after ICP etching. The nanoholes have inverted-cone-shaped form with a top diameter of about $50 \mathrm{~nm}$ and a depth of about $64 \mathrm{~nm}$ after $40 \mathrm{~s}$ etching. The inset in (b) shows a magnification of the inverted-cone-shaped nanoholes.

the nanohole arrays are measured to be about $16,48,64$, and $95 \mathrm{~nm}$ for 10, 30, 40, and $60 \mathrm{~s}$ etching times, respectively.

Figure 3(a) shows the reflectance spectra at the surface of the fabricated solar cell with and without the nanohole arrays. It can be seen that all nanopatterned surfaces have lower reflectances compared to the planar surface in the measured wavelength regions. In addition, the reflectance is reduced with the increase of the hole depth. The reduction of the reflectance at the nanopatterned surfaces may originate from the two possible mechanisms. The first one is based on the redistribution of the incident light. When the incident light comes to the solar cell surface with the nanohole arrays, it can be scattered by the subwavelength holes and will be redistributed. This redistribution results in a reduction of the reflectance at the textured surface $[16,17]$. The second mechanism is based on the Fresnel reflection suppression [17], that is, a gradual change in the refractive index along the surface with the ICS nanoholes. The ICS nanohole structure may result in a Fresnel reflection suppression when the incident light comes to the solar cell surfaces. Figure 3(b) shows the calculated effective refractive indices near the surfaces of the solar cells with and without the ICS nanohole arrays at a wavelength of $600 \mathrm{~nm}$ [18]. In the non-patterned solar cell with a planar InGaP window layer, the refractive index changes sharply from air $\left(n_{\text {air }}=1\right)$ to $\operatorname{InGaP}\left(n_{\mathrm{InGaP}}=\right.$ $3.62)$ at $600 \mathrm{~nm}$. When the ICS nanoholes are fabricated on the InGaP window layer, the refractive index changes gradually because the hole diameter reduces continuously from the top to the bottom. Because the reflection from an interface between two materials with refractive indices of $n_{1}$ and $n_{2}$ is proportional to $\left(n_{1}-n_{2}\right)^{1 / 2}$ [19], the refractive index gradient exhibited by the nanohole arrays leads to a lower reflection over a wavelength range of interest.

Figure 4 shows the external quantum efficiency (EQE) of the GaAs solar cells with and without the nanohole arrays at different wavelengths. It reveals that the EQE of the nanohole patterned solar cell is enhanced in the long wavelength region near the bandgap energy of GaAs (700-900 nm), while this value is slightly reduced in the short wavelength region compared to that of the planar surface solar cell. In the long wavelength region, the photocurrent can be further increased as the nanohole array depths increase. This may be attributed to a better light trapping with the deeper nanohole arrays. In the short wavelength region, the loss of high energy photons by thermalization and surface recombination due to the increased surface states of the $\mathrm{InGaP}$ window layer is more dominant than the efficiency gain by light trapping effect $[13,20]$. However, this reduction is small compared to the enhancement of EQE at the long wavelength region in the solar cells with the nanohole arrays. As a result, the total conversion efficiency of the solar cell with the deeper nanohole arrays shows a higher value compared to that of the planar or shallow patterned solar cell, as shown in Figure 5.

Figure 5 shows the $J-V$ characteristics of the GaAs singlejunction solar cell with and without the nanohole arrays. The corresponding parameters are summarized in Table 1. It can be seen that the photovoltaic characteristics vary with the depth of the nanohole arrays. Especially, the short-circuit current density $\left(J_{\mathrm{sc}}\right)$ changes a lot compared to the other parameters due to the lower reflection. $J_{\mathrm{sc}}$ is increased up to $7.2,10.4,11.6$, and $12.9 \%$ when the depths of the nanohole arrays on the surface of the GaAs solar cell are 16, 48, 64, and $95 \mathrm{~nm}$, respectively. However, it is found that fill factor $(\mathrm{FF})$ and open-circuit voltage $\left(V_{\mathrm{oc}}\right)$ are degraded when the nanohole depth increases. This may be attributed to the plasma-induced damage during the anisotropic etching process [21]. The damage is a complex function of many plasma characteristics such as the plasma energy, chemistry of plasma gas, pressure, and temperature. The plasmainduced surface states can cause a significant increase of carrier recombination at the etched surfaces and a decrease of the carrier life time, in turn, resulting in the reduction of the photocurrent. Taking into account the competition between the reduction of reflectance and the plasma damages by the deep nanohole arrays, we found that about $64 \mathrm{~nm}$ hole depth is the optimized value for the improvement of conversion efficiency in the studied system. The conversion efficiency improved from 10.53 to $11.57 \%$ under 1-sun AM $1.5 \mathrm{G}$ conditions by using $64 \mathrm{~nm}$ deep hole arrays.

\section{Conclusion}

In summary, the ICS nanohole arrays with the depths of $16,48,64$, and $95 \mathrm{~nm}$ have been fabricated on the InGaP 


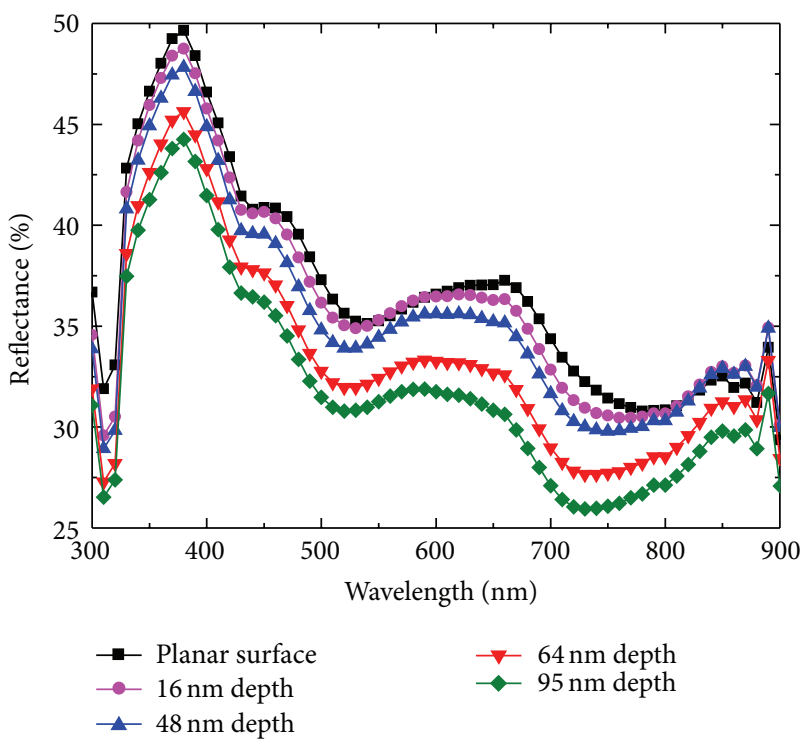

(a)

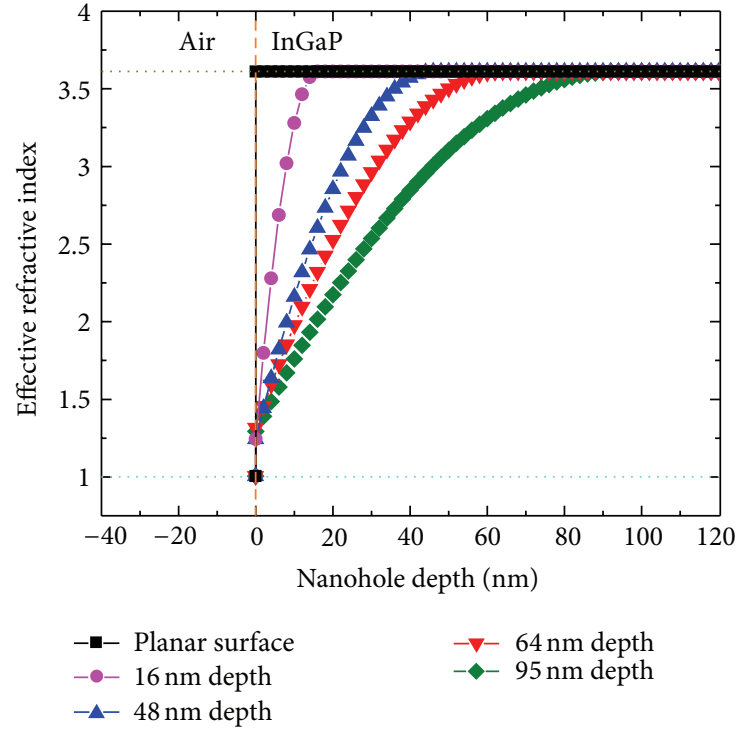

(b)

Figure 3: (a) Reflectance spectra at the surfaces of the solar cells with and without nanohole arrays and (b) calculated effective refractive index at $\lambda=600 \mathrm{~nm}$ near the surface of the solar cells with and without inverted-cone-shaped nanoholes.

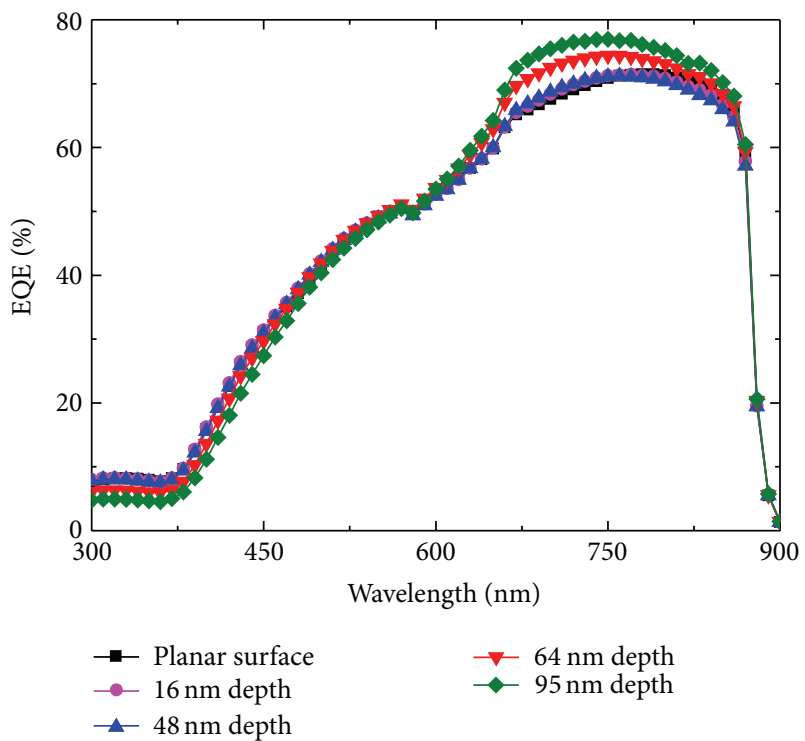

FIGURE 4: EQE of the solar cells with and without the nanohole arrays.

window layer of the GaAs single-junction solar cells using the AAO masks. Characteristics of the solar cells with and without the nanohole arrays have been investigated by the reflectance, external quantum efficiency, and current density-voltage curve measurements. The solar cells with the nanohole arrays show a lower surface reflectance compared to the unpatterned planar sample. The surface reflection is reduced with the increase of the nanohole depth. The external

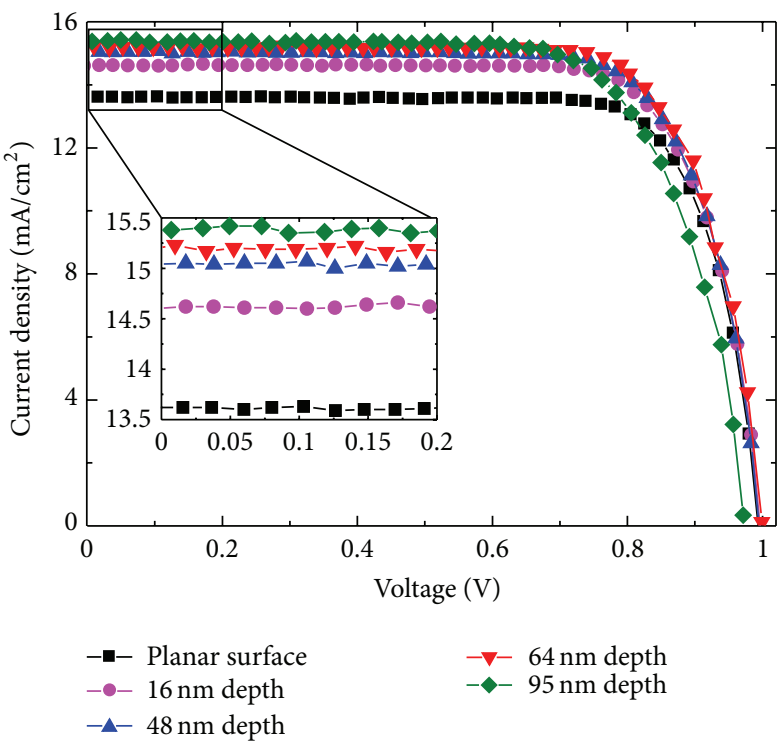

FIGURE 5: $J-V$ curves of the GaAs solar cells with and without the nanohole arrays.

quantum efficiency of the solar cell with the nanohole arrays is improved at the wavelength region near the GaAs bandgap energy due to the enhanced light absorption. The current density-voltage characteristics of the solar cells show that the conversion efficiency can be increased from 10.53 to $11.57 \%$ under the AM $1.5 \mathrm{G}$ conditions by using the $64 \mathrm{~nm}$ deep ICS nanohole arrays. 
TABLE 1: Current density-voltage characteristics of the GaAs singlejunction solar cells with various depths of the nano-hole arrays.

\begin{tabular}{lcccc}
\hline Sample & $V_{\mathrm{oc}}(\mathrm{V})$ & $J_{\mathrm{sc}}\left(\mathrm{mA} / \mathrm{cm}^{2}\right)$ & FF (\%) & Eff. (\%) \\
\hline Planar surface & 0.994 & 13.622 & 77.81 & 10.53 \\
16 nm depth & 0.996 & 14.605 & 76.55 & 11.14 \\
$48 \mathrm{~nm}$ depth & 0.995 & 15.044 & 75.87 & 11.36 \\
64 nm depth & 1.009 & 15.206 & 75.39 & 11.57 \\
$95 \mathrm{~nm}$ depth & 0.973 & 15.373 & 72.52 & 10.85 \\
\hline
\end{tabular}

\section{Acknowledgments}

This work is supported by the Converging Research Center Program through the National Research Foundation (NRF) of the Korea funded by the Ministry of Education, Science and Technology (Grant no. 2011K000590). This work is also supported by the New \& Renewable Energy of the Korea Institute of Energy Technology Evaluation and Planning (KETEP) grant funded by the Korea government Ministry of Knowledge Economy (Grant no. 20123010010110).

\section{References}

[1] C.-H. Sun, B. J. Ho, B. Jiang, and P. Jiang, "Biomimetic subwavelength antireflective gratings on GaAs," Optics Letters, vol. 33, no. 19, pp. 2224-2226, 2008.

[2] D. Li, F. Huang, and S. Ding, "Sol-gel preparation and characterization of nanoporous $\mathrm{ZnO} / \mathrm{SiO}_{2}$ coatings with broadband antireflection properties," Applied Surface Science, vol. 257, no. 23, pp. 9752-9756, 2011.

[3] G. Zhang, J. Zhao, and M. A. Green, "Effect of substrate heating on the adhesion and humidity resistance of evaporated $\mathrm{MgF}_{2} / \mathrm{ZnS}$ antireflection coatings and on the performance of high-efficiency silicon solar cells," Solar Energy Materials and Solar Cells, vol. 51, no. 3-4, pp. 393-400, 1998.

[4] M. H. Kang, K. Ryu, A. Upadhyaya, and A. Rohatgi, "Optimization of SiN AR coating for Si solar cells and modules through quantitative assessment of optical and efficiency loss mechanism," Progress in Photovoltaics, vol. 19, no. 8, pp. 983990, 2011.

[5] J. Zhu, Z. Yu, S. Fan, and Y. Cui, "Nanostructured photon management for high performance solar cells," Materials Science and Engineering R, vol. 70, no. 3-6, pp. 330-340, 2010.

[6] K.-S. Han, J.-H. Shin, W.-Y. Yoon, and H. Lee, "Enhanced performance of solar cells with anti-reflection layer fabricated by nano-imprint lithography," Solar Energy Materials and Solar Cells, vol. 95, no. 1, pp. 288-291, 2011.

[7] Y.-F. Huang, S. Chattopadhyay, Y.-J. Jen et al., "Improved broadband and quasi-omnidirectional anti-reflection properties with biomimetic silicon nanostructures," Nature Nanotechnology, vol. 2, no. 12, pp. 770-774, 2007.

[8] H. A. Atwater and A. Polman, "Plasmonics for improved photovoltaic devices," Nature Materials, vol. 9, no. 3, pp. 205213, 2010.

[9] E. Yablonovitch, "Inhibited spontaneous emission in solid-state physics and electronics," Physical Review Letters, vol. 58, no. 20, pp. 2059-2062, 1987.

[10] C. Trompoukis, O. E. Daif, V. Depauw, I. Gordon, and J. Poortmans, "Photonic assisted light trapping integrated in ultrathin crystalline silicon solar cells by nanoimprint lithography," Applied Physics Letters, vol. 101, Article ID 103901, 4 pages, 2012.

[11] I. Prieto, B. Galiana, P. A. Postigo, C. Algora, L. J. Martínez, and I. Rey-Stolle, "Enhanced quantum efficiency of Ge solar cells by a two-dimensional photonic crystal nanostructured surface," Applied Physics Letters, vol. 94, no. 19, Article ID 191102, 2009.

[12] J. Liang, H. Chik, A. Yin, and J. Xu, “Two-dimensional lateral superlattices of nanostructures: nonlithographic formation by anodic membrane template," Journal of Applied Physics, vol. 91, no. 4, pp. 2544-2546, 2002.

[13] A. Polman and H. A. Atwater, "Photonic design principles for ultrahigh-efficiency photovoltaics," Nature Materials, vol. 11, no. 3, pp. 174-177, 2012.

[14] M. Jung, S.-I. Mho, and H. L. Park, "Long-range-ordered $\mathrm{CdTeGaAs}$ nanodot arrays grown as replicas of nanoporous alumina masks," Applied Physics Letters, vol. 88, no. 13, Article ID 133121, 2006.

[15] S. Ohki, M. Oda, H. Akiya, and T. Shibata, "Cavernous undercuts appearing in reactive ion etched submicron-wide deep trenches," Journal of Vacuum Science \& Technology B, vol. 5, pp. 1611-11616, 1987.

[16] W. Stork, N. Streibl, H. Haidner, and P. Kipfer, "Artificial distributed-index media fabricated by zero-order gratings," Optics Letters, vol. 16, pp. 1921-1923, 1991.

[17] D. H. Raguin and G. M. Morris, "Antireflection structured surfaces for the infrared spectral region," Applied Optics, vol. 32, no. 7, pp. 1154-1167, 1993.

[18] D. G. Stavenga, S. Foletti, G. Palasantzas, and K. Arikawa, "Light on the moth-eye corneal nipple array of butterflies," Proceedings of the Royal Society B, vol. 273, no. 1587, pp. 661-667, 2006.

[19] P. Nubile, "Analytical design of antireflection coatings for silicon photovoltaic devices," Thin Solid Films, vol. 342, no. 1, pp. 257261, 1999.

[20] K. Cho, D. J. Ruebusch, M. H. Lee et al., "Molecular monolayers for conformal, nanoscale doping of InP nanopillar photovoltaics," Applied Physics Letters, vol. 98, no. 20, Article ID 203101, 2011.

[21] K. N. Lee, J. W. Lee, J. Hong, C. R. Abernathy, S. J. Pearton, and W. S. Hobson, "Effect of ion damage on the electrical and optical behavior of p-type GaAs and InGaP," Journal of Electronic Materials, vol. 26, no. 11, pp. 1279-1282, 1997. 

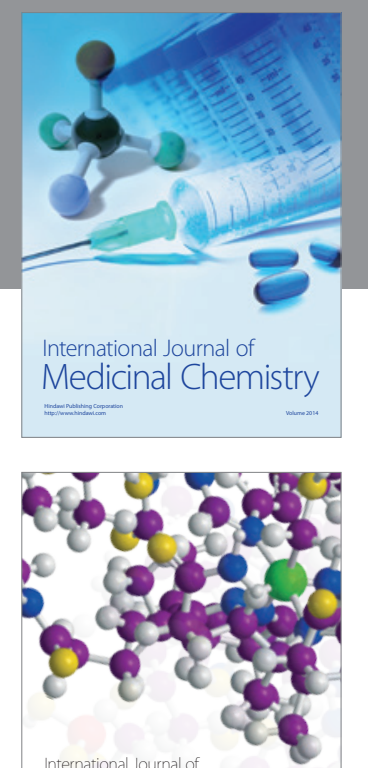

\section{Carbohydrate} Chemistry

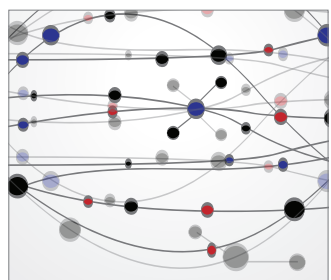

The Scientific World Journal
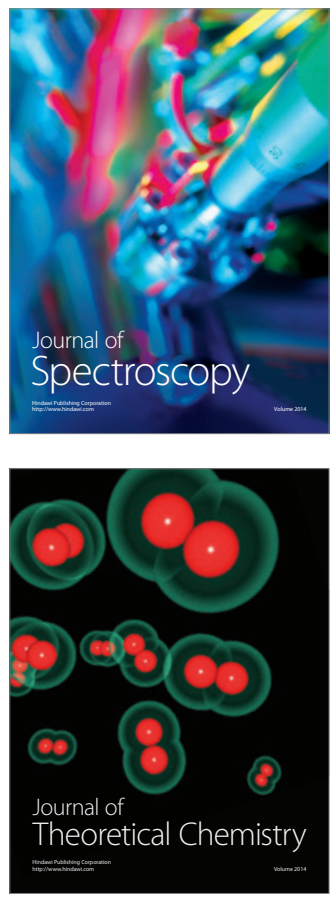
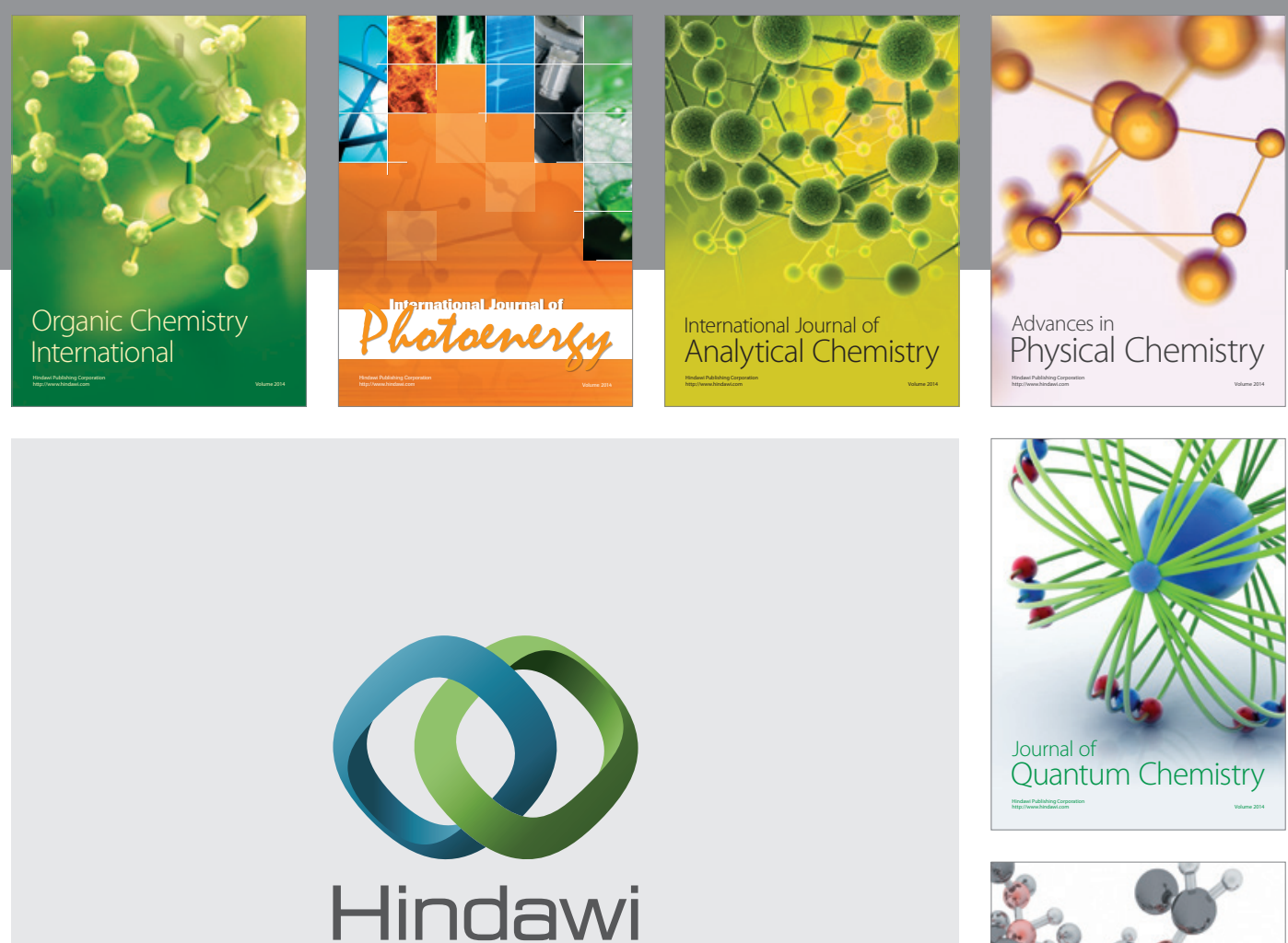

Submit your manuscripts at

http://www.hindawi.com

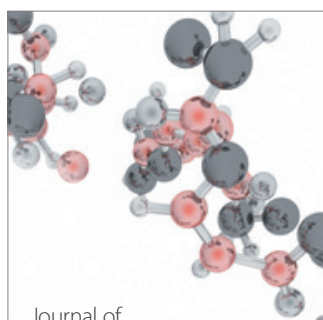

Analytical Methods

in Chemistry

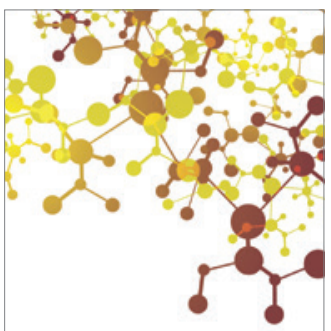

Journal of

Applied Chemistry

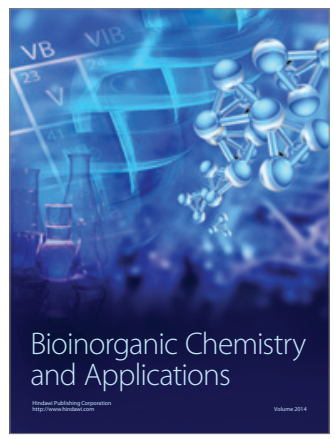

Inorganic Chemistry
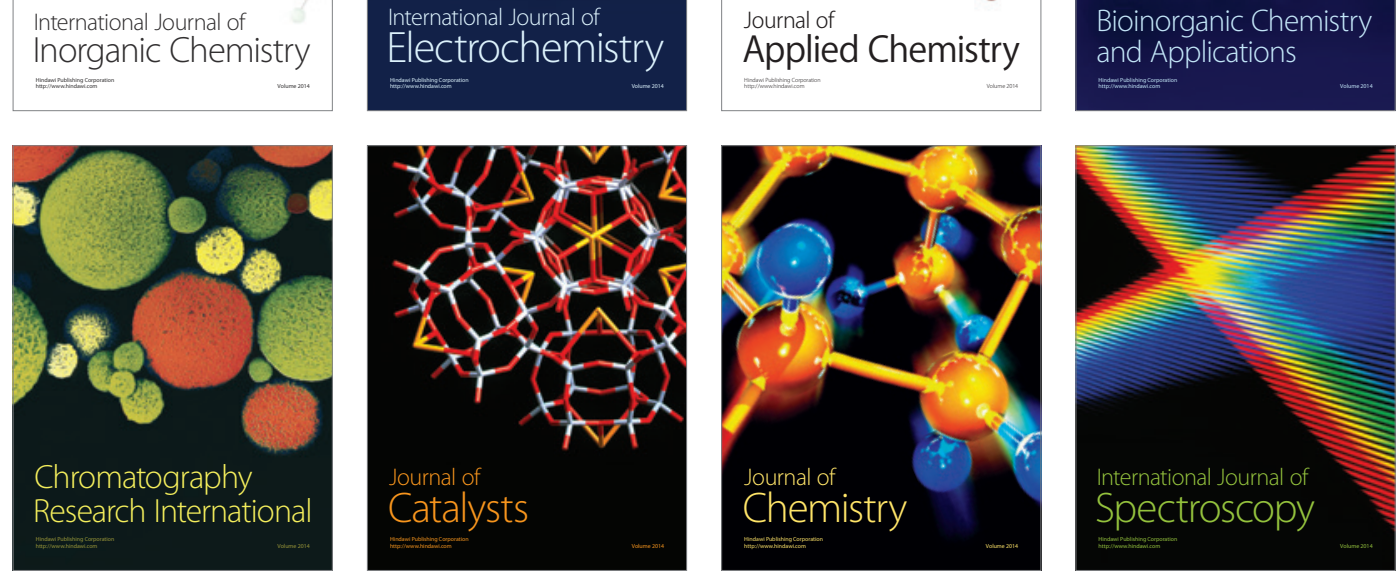